\title{
CULTURA E LAZER: UMA APROXIMAÇÃO HABERMASIANA
}

\author{
Gustavo Gutierrez e Marco Bettine de Almeida
}

Este texto apresenta uma análise sociológica do lazer em condições específicas, ou seja, do lazer vivenciado por detentos dentro do sistema prisional. Utiliza, como referencial metodológico, uma leitura das categorias habermasianas de mundo da vida e sistemas dirigidos pelos meios poder e moeda, e suas respectivas manifestações nas formas de ação comunicativa ou estratégica. Para efeito deste texto adotamos parte da influência weberiana em Habermas no que diz respeito a privilegiar a percepção da racionalidade do sujeito da ação social, embora mediada pela palavra e busca argumentativa, tanto da construção de consensos no meio comunicativo, como da obtenção de um comportamento útil no meio estratégico.

A escolha do tema, apesar de inusual, procura atender aos objetivos mais amplos da nossa construção teórica. Há no campo de pesquisa em lazer uma tradição importante que agrega a possibilidade da existência de práticas lúdicas, após a revolução industrial, à liberação do tempo de trabalho. Neste sentido, o lazer é fundamentalmente uma alternativa, ou decorrência, do tempo de trabalho. Este não é um fato isolado, mas se inscreve no cenário mais amplo da vigência do trabalho como categoria macrosociológica determinante, muito presente na 
pesquisa em ciências sociais durante todo o século vinte, ou pelo menos até a queda do Muro de Berlim e, a assim denominada, crise de paradigmas. O presídio, pelo menos na situação brasileira, exclui a concepção de tempo de trabalho o que, por decorrência lógica, também exclui a prática do lazer, pelo menos na acepção mais clássica do termo. Neste sentido, lazer no presídio, enquanto recorte do real, constitui por si só um questionamento dos conceitos mais utilizados no campo.

Outro aspecto que deve ser inicialmente apontado é o próprio sistema prisional. Procuramos adotar aqui uma aproximação distinta das concepções mais comuns, que o definem como uma organização isolada do resto da sociedade, visando à subjugação do corpo ou à construção de um corpo disciplinado. A pesquisa sobre a produção teórica a respeito da prisão aparece como referência importante para uma aproximação ao objeto, mas não se esperava encontrar nela a confirmação dos pressupostos básicos adotados para esta 94 pesquisa, nem tampouco essa literatura foi utilizada com uma expectativa esclarecedora do que viria a ser encontrado na realidade concreta, inclusive porque o referencial teórico básico provém de uma leitura das categorias habermasianas.

Este texto, portanto, apresenta uma análise sociológica que procura, através de uma pesquisa de campo sobre o lazer no presídio, avançar na pesquisa de aspectos relevantes da realidade contemporânea, conforme descrito a seguir.

\section{A crítica à dicotomia lazer-trabalho}

\section{Lazer enquanto objeto da sociologia}

O lazer, enquanto objeto de pesquisa, não despertou enorme interesse no transcorrer do século XX. Muitos outros aspectos da vida em sociedade mereceram mais dedicação e trabalho intelectual no período como, por exemplo, as formas de organização do trabalho, os sindicatos, os movimentos sociais ou até mesmo a sensualidade. A atividade 
lúdica, a diversão propriamente dita, não atraiu muitos pesquisadores enquanto aspecto da sociabilidade que mereça esforços sistemáticos, coletivos e continuados de reflexão. Um argumento ilustrativo neste sentido é o fato de o Dicionário de Ciências Sociais da Fundação Getúlio Vargas, uma obra de referência escrita com cuidado, não contemplar o verbete lazer ou lúdico (Silva, 1987).

Existe, contudo, uma linha de pesquisa sobre o objeto lazer no Brasil marcada pelo pensador francês Jofre Dumazedier. Este autor, assim como a grande maioria de seus contemporâneos, compartilha uma percepção do social a partir do que se convencionou chamar sociedade do trabalho, em continuidade à tradição do pensamento clássico nas ciências sociais. Isto o leva a só perceber o lazer, enquanto atividade distinta e específica da vida social, com o advento da Revolução Industrial e a segregação dos espaços de convivência familiar, comunitários e profissionais, ou seja, vamos encontrar na história da definição do lazer um aspecto genético de "não-trabalho". É uma definição baseada na observação da sociedade constituída na modernidade, e que traz em seu bojo a marca da mesma valorização da categoria trabalho que vamos encontrar nas obras de Durkheim, Marx e Weber.

Na década de noventa, como decorrência do processo de globalização, ou mundialização, que se segue à queda do Muro de Berlim, vamos presenciar uma transformação na pesquisa sociológica expressa como uma crise de paradigmas, ou pelo menos uma crítica importante ao poder sociologicamente macro determinante da categoria trabalho, na expressão divulgada por Claus Offe em "Trabalho e sociedade: problemas estruturais e perspectivas para a sociedade do trabalho" (1989). Esta tendência já podia ser previamente percebida, no campo das Ciências Sociais, em autores importantes como Foucault e Habermas, entre outros. Talvez o texto que antecede as mudanças da forma mais clara possível seja o livro de André Gorz (1982), pesquisador 
de longa tradição marxista, cujo título enfático não deixa lugar a muitas dúvidas: "Adeus ao Proletariado: para além do Socialismo”. Ricardo Antunes (1995), num livro cujo título parafraseia o de Gorz, "Adeus ao trabalho? Ensaio sobre a metamorfose e centralidade do mundo do trabalho", faz um apanhado abrangente desta produção intelectual ao mesmo tempo em que busca demonstrar suas deficiências.

A crise de paradigmas, ou a descentralidade da categoria trabalho, não levou a uma revalorização da categoria lazer, ao contrário do que poderia se pensar a partir de uma análise rápida e mecânica. Isto se deve basicamente a dois fatores fundamentais e interligados. Em primeiro lugar porque a própria tradição de pesquisa sobre lazer constitui-se tendo como referência a sociedade do trabalho, a exemplo da definição já apontada. E, em segundo lugar, porque, ao tentar pensar o social desde uma perspectiva desvinculada da categoria trabalho, ou onde a categoria trabalho vai entrar em 96 igualdade de condições com as demais esferas da vida social, a alternativa mais simples e lógica para o pesquisador era adotar categorias de análise mais abrangentes, com uma tradição de pesquisa mais antiga e rica, como as do campo da cultura. Isto é, quando parte significativa dos pesquisadores do campo das ciências humanas chega a um consenso relativo quanto à necessidade de uma revisão de paradigmas, que diminua a centralidade da categoria trabalho, pode-se pensar que o lazer, enquanto seu oposto por assim dizer, vai ser valorizado na análise na mesma proporção em que a categoria trabalho perde espaço. Este é o tipo de raciocínio mecânico que funciona mal ao tratarmos de questões humanas. A concepção corrente de lazer está geneticamente marcada pela idéia da sociedade do trabalho, enquanto outras categorias importantes apresentam um desenvolvimento mais rico e independente, tornando-as, portanto, mais interessantes para o pesquisador engajado neste processo de tentar superar a centralidade da categoria trabalho na pesquisa teórica. 
A título de ilustração, o mesmo Dicionário de Ciências Sociais, que não contempla verbetes lazer ou lúdico, apresenta um verbete detalhado sobre estilo de vida, incorporando contribuições de Veblen e Bourdieu, além de destacar a importância do estilo de vida para explicar a estratificação social dentro do sentido weberiano de classe social.

Urge repensar o lazer, mas para efeito deste texto é importante ter presente que existe uma reflexão sobre o lazer, hegemônica durante parte da segunda metade do século passado, a partir da perspectiva da sociedade do trabalho, ou seja, uma reflexão apoiada na dicotomia lazer-trabalho.

\section{Lazer e trabalho}

O lazer no Brasil se sistematiza enquanto campo de conhecimento a partir da década de 1970 (Requixa, 1980). A construção do campo teórico ocorreu pela incorporação das discussões de Joffre Dumazedier e Stanley Parker. Estes autores dialogavam com a categoria trabalho, tendo-a como referência para pensar o lazer. Surge deste diálogo a dicotomia Lazer-Trabalho. Os autores definiam o lazer como contraponto ao trabalho, como sua antítese. O lazer seria assim o tempo ganho sobre o trabalho, destacando a importância dos trabalhadores na conquista deste tempo.

Para Dumazedier (1979, p. 34), o lazer nada mais é que o conjunto de ocupações às quais o indivíduo pode entregarse de livre vontade, seja para repousar, divertir-se, recrear-se, entreter-se ou informar-se, após desembaraçar-se das obrigações profissionais. Para Dumazedier, o lazer moderno não é apenas o acesso democrático ao tempo livre, antigo privilégio das classes dominantes. Ele saiu da própria organização do trabalho burocrático e industrial. O tempo de trabalho, enquadrado em horários fixos, permanentes, independente das estações do ano, se retraiu sob o impulso do movimento sindical e segundo a lógica de uma economia de consumo. Em relação ao primeiro, o lazer seria para repousar e descansar da jorna- 
da de trabalho; pelo segundo, o lazer seria o momento mais propício de consumo dos bens produzidos. De uma ou de outra forma o lazer é um tempo ganho sobre o trabalho.

Considera-se o tempo utilizado para as diferentes obrigatoriedades sociais (família, escola, cursos, religião e lazer) como tempo disponível, e o lazer como um tempo específico dentro do tempo disponível (Marcellino, 1987, p. 20). O objeto lazer, neste modelo, é o conjunto de atividades individuais ou coletivas voltadas para a satisfação de uma série de interesses - no plano de criação, formação e aprimoramento pessoal, entretenimento, descanso etc. - realizadas no tempo liberado das obrigações impostas pelo trabalho profissional e por outras responsabilidades sociais.

Em linhas gerais, a dicotomia lazer-trabalho foi estudada principalmente a partir de duas definições básicas. A primeira visão discute o lazer como objeto que auxilia ou afasta o sujeito social da sua emancipação. Como exemplo pode98 mos citar Paul Lafargue e seu conhecido "Elogio ao Ócio". Na mesma linha de relacionar lazer e emancipação, apesar de conterem diferenças importantes, temos ainda Dumazedier, Marcellino, Requixa; e pesquisas que definem o lazer com o auxílio de categorias relacionadas à cultura de massa, sua transformação em mercadoria e seu caráter fetichista, a exemplo de Morin, Musse e Werneck. Já na segunda visão, o lazer serviria como fonte inspiradora e aceleradora do trabalho (Walsh, 1986), alimentando os ganhos da economia de um país, agregando criatividade à tecnologia e ao desenvolvimento (Murphy, Niepoth e Jamieson, 1991).

As discussões sobre a descentralidade da categoria trabalho, mais divulgadas a partir do final da década de 1980, apontam para uma revalorização interna entre as diferentes dimensões da vida em sociedade na construção de modelos de explicação, incorporando com mais força aspectos como o distanciamento do Estado na mediação dos conflitos socioeconômicos, o desemprego, a implantação do setor de ser- 
viços, as privatizações das atividades estatais e a abertura da economia. Novas teorias, ou pelo menos tentativas sistematizadas de explicações teóricas, passam a enfatizar diferentes instituições sociais contemporâneas, a exemplo de grupos de convivência, relações pessoais, transformações tecnológicas ou a incorporação de novos hábitos, como aponta Giddens, juntamente com as inúmeras possibilidades que os indivíduos possuem para se integrar a elas, onde a esfera econômica representa somente uma das faces importantes, porém não necessariamente determinantes, da sociedade (Habermas, 1987). As outras faces são: as expressões simbólicas, os valores culturais e a linguagem (Habermas, 1989).

\section{Alternativas à dicotomia lazer-trabalho.}

Para Elias e Dunning (1992, p. 145), o lazer é entendido como um tipo de atividade inserida no tempo livre. Pensam o lazer pelo seu caráter decisional. Os autores colocam o indivíduo como principal articulador, podendo dar sentido à sua atividade e aproximá-la da busca da excitação ou do prazer (Almeida e Gutierrez, 2005). O lazer, apesar de trabalhar no limite do descontrole, está intimamente ligado às dimensões sociais para cada situação, por exemplo, no estádio de futebol onde são permitidos os xingamentos e atitudes não convencionais. Segundo Elias e Dunning (1992, p. 170), o lazer funcionaria na forma de estimulação social, a estimulação como fonte fundamental da atividade de lazer e, por conseqüência, do prazer. A apropriação tardia da obra de Norbert Elias no Brasil vem corroborar a tese de que o lazer não foi um dos objetos das ciências sociais tratado com mais atenção, no transcorrer das últimas décadas.

Outra tendência recente nas discussões sobre lazer é marcada pela idéia da pós-moderna-idade e a falência dos metarelatos (Almeida, 2007). Apesar de estas teorias se aproximarem do conceito de um sujeito hedonista, elas não discutem o lazer numa perspectiva macro-social. Não tendo uma meto- 
dologia clara, ou um marco conceitual único, a percepção pós-moderna do lazer vai agregar, à definição tradicional de lazer (como busca pessoal e não produtiva do prazer no tempo livre), características do mundo atual como a ênfase na competição e no personalismo, a sobrevalorização da aparência, a intranscendentalidade dos valores e o esporte de aventura. Estes estudos, justamente por não adotarem uma linha teórica melhor definida, encontram no objeto lazer a possibilidade de levar a idéia da exaltação do pastiche, enquanto colagem descompromissada dos mais diferentes autores e escolas de pensamento, ao seu limite máximo.

Habermas, na Teoria da Ação Comunicativa, também oferece a possibilidade de construir um entendimento do lazer superando a dicotomia lazer-trabalho. Aqui o lazer estaria fundamentado e definido a partir da sociabilidade espontânea, constituída no mundo da vida, e não no mundo do trabalho presente no sistema poder e moeda. O lazer e o trabalho, a 100 partir de uma visão influenciada por Habermas, encontram-se em marcos conceituais distintos, isto é, enquanto o princípio do lazer encontra-se no mundo da vida, o trabalho está nos sistemas dirigidos pelos meios poder e moeda, com ênfase para o sistema moeda característico das relações econômicas ${ }^{1}$.

Partindo do princípio de que o prazer pode manifestar-se em qualquer relação ou presença humana, sua possibilidade atravessa tanto o mundo da vida como os sistemas dirigidos pelos meios. Deste modo, o lazer é determinado historicamente e possui uma característica essencial imutável que é a busca do prazer (Gutierrez, 2001) enquanto elemento fundamental e distintivo. O lazer, segundo esta interpretação,

\footnotetext{
${ }^{1}$ O Mundo da vida e os Sistemas estão integrados no entendimento geral de sociedade contemporânea, o Mundo da Vida se caracteriza por ações comunicativas, e o Sistema, pelas ações estratégicas. Apesar de a sociedade contemporânea definirse pela dualidade Sistemas e Mundo da Vida, o primeiro, para existir, ancora-se e coloniza o segundo através de uma diferenciação sistêmica, transformando modos comunicativos em estratégicos (Almeida e Gutierrez, 2004).
} 
caminha juntamente com a evolução social, a transformação do mundo da vida e a inovação do sistema. O lazer caracterizado como prática de consumo no mercado manifesta-se no âmbito do sistema dirigido pelo meio moeda, enquanto formas de lazer ligadas à cultura e à interação espontânea e livre de pessoas e grupos manifestam-se no espaço do mundo da vida. A interpretação do objeto lazer, incorporando a contribuição habermasiana, permite assim a superação da dicotomia lazer-trabalho de uma forma original (Almeida e Gutierrez, 2004). Não se trata mais de contrapor, de um lado o lazer alienado e fetichista do mercado de consumo e, do outro, um lazer autêntico e emancipador presente na cultura popular, ou ainda numa prática revolucionária.

\section{Lazer e presídio}

O lazer e o presídio, em uma análise rápida, expõem-se em opostos. O lazer é entendido e imaginado como o oposto das imagens vinculadas às penitenciárias, onde assistimos ao ilícito, à prostituição e à degradação social. Para não ficarmos nesta visão, trabalhar-se-á com o lazer na perspectiva das categorias Sistemas Dirigidos pelos Meios Poder e Moeda, e o Mundo da Vida. O lazer se caracteriza pela busca de um prazer, que pode ou não ser consumado, pensando o sujeito da ação social como agente histórico, que segue sua vontade a partir do livre arbítrio, nos limites da sua visão simbólica e padrões culturais, restrito às sanções e normas sociais, num contexto de limitações de ordem material e conflitos individuais, entre grupos e classes. No presídio, esta visão ampla servirá de base para integrarmos a idéia de lazer, enquanto busca do prazer, em um contexto de reclusão. Estudos de Playfard e Goffman apontam o presídio como tenebrosamente estático, ou reprodutor do ilícito pelos padrões de força, linguagem e grupos. A intenção é decodificar o papel desempenhado por algumas atividades de lazer para promover outros olhares da reclusão. 
As teorias decorrentes da dicotomia lazer-trabalho não facilitam uma relação entre o lazer e o presídio. Aqui o espaço de reclusão promove o ócio; as atividades desenvolvidas são terapêuticas e não de lazer; o trabalho do preso não se insere no modelo produtivo e tem como objetivo saldar os gastos do Estado, possuindo características de reprodução do ilícito; o tempo de não trabalho tem a função de "pagamento" do seu erro para sociedade, segundo o código penal e a lei de execução penal; o tempo das obrigações na reclusão não teria um contraponto, isto é, o preso só possui o tempo de privação de liberdade; o espaço, em uma instituição fechada, impede a existência do lazer, por não existir a característica de livre escolha e movimento.

Alguns pontos nevrálgicos de autores de referência da pesquisa, tanto sobre lazer como sobre o presídio, inibem a possibilidade de discutir o lazer dos presos. Tanto autores que pensam o sistema prisional, como Playfard (1969) e 102 Goffman (1996), como autores que pensam o lazer, a exemplo de Dumazedier (1979) e Marcellino (1987), trabalham com a tese da dicotomia lazer-trabalho, ou, ainda, de que o mundo encarcerado é um arquipélago de símbolos e ritos. Neste sentido, o lazer surge como algo inviável no presídio em função de (a) ao adotar a tese do trabalho como contraponto que define o lazer, ou como elemento constituinte fundamental para existência do lazer, o preso, por não trabalhar, não possui lazer; (b) as atividades dos presos seriam recreativas, não caracterizando, portanto, lazer; (c) ou ainda através de uma visão que percebe o presídio como arquipélago de ritos e símbolos

Com relação ao primeiro argumento (a), o modelo habermasiano permite compreender as relações de trabalho a partir da sua ligação com as ações estratégicas na sociedade, entendidas como manifestações características dos sistemas dirigidos pelos meios poder e moeda, que existem a partir de uma relação de instrumentalização e empo- 
brecimento das ações originais do mundo da vida, num processo de colonização da sua riqueza simbólica. O sistema agrega ações do tipo estratégico, sem priorizar o consenso, através do cálculo egocêntrico de ressarcimentos e prejuízos efetuado pelo sujeito da ação social. No mundo da vida, por sua vez, encontramos uma concepção de totalidade das relações interpessoais através da comunicação, e o respeito às normas aceitas pelos agentes da ação da fala e às formas subjetivas de convivência entre os pares. Assim, o trabalho e o não-trabalho no presídio não constituem fatores limitantes, ou condicionantes, para a presença do lazer já que sua definição se dá através das características originais das relações do Mundo da Vida. Como escreve Habermas:

"não existe nenhuma forma de vida sócio-cultural que não esteja pelo menos implicitamente orientada para o prosseguimento do agir comunicativo com meios argumentativos - por mais rudimentar que tenha sido o desenvolvimento das formas de argumentação e por mais pobre que tenha sido a institucionalização dos processos discursivos do entendimento mútuo. Tão logo as consideremos como interações reguladas de maneira especial, as argumentações dão-se a conhecer como forma de reflexão do agir orientado para o entendimento mútuo" (1989, p. 123).

$\mathrm{O}$ segundo ponto $(\mathrm{b})$ refere-se às atividades dos presos como recreativas e não de lazer. A busca do prazer é o elemento fundamental para a constituição do lazer e recrear-se parte também deste pressuposto. Esta separação foi idealizada pelos autores das teorias dicotômicas, com o intuito de dividir as atividades lúdicas no ambiente de obrigação social, isto é, as atividades de lazer seriam as que ocorrem no tempo disponível e recreação seriam as atividades das obrigações sociais. Por isso as atividades lúdicas no presídio poderiam ser consideradas recreativas. Como o lazer 
não será aqui definido como contraponto ao trabalho e sim pelo mundo das relações e da sociabilidade espontânea, não cabe usar esta definição para o lazer dos presos.

O terceiro ponto (c) se refere ao presídio como arquipélago de ritos e símbolos. Nestes termos, os autores não entendem o apenado como única e exclusivamente privado de liberdade. Este sujeito encarcerado não deixa de ser humano quando preso, conseqüentemente, o mundo do encarcerado não é um arquipélago de símbolos e ritos. Ao considerar o preso como sujeito histórico, transformador e comunicativo, que busca auferir prazer como qualquer outra pessoa, pode-se afirmar que existe lazer no presídio e que o lazer na reclusão determina a situação do preso e grupo que o sujeito representa, fazendo, desta maneira, parte da cultura prisional.

A partir desta análise, entenderemos o lazer dos presos através do fenômeno da prisionização, pois o lazer é incorporado na prisionização e integra-se a partir das normas

104 do grupo. Em outras palavras, as atividades desenvolvidas pelos presos refletem uma ótica a partir do ilícito pela lei e sociedade, onde ocorre a reprodução de um certo tipo de linguagem e modos de relacionamento interno. No caso, fala-se "das leis dos cativos" entre os cativos. O lazer estudado será um lazer dos cativos. Isto é, o lazer do preso é prisionizado e as características discutidas do prazer, do lúdico e do indivíduo, deverão ser intermediadas com o intuito de decodificar os códigos presentes no espaço de reclusão, aproximando o lazer encarcerado ao lazer do encarcerado. Isto é, todas as atividades desenvolvidas passam por um filtro simbólico dos detentos que, necessariamente, reproduzem a sua linguagem, os seus ritos e as formas de poder e submissão, tanto entre os detentos e instituição como entre eles.

\section{Aproximação teórica ao objeto presídio}

A apreensão científica do real se dá através da construção de modelos teóricos que, uma vez confrontados com os objetos 
que procuram explicar, demonstram possuir conteúdo de verdade, no estágio de desenvolvimento do campo de conhecimento. No caso específico das ciências humanas, alguns conceitos fundamentais dependem de uma opção prévia de natureza filosófica, já que não podem ser comprovados empiricamente. É o caso da definição da natureza das relações sociais e do próprio ser humano. Por isso, não há um consenso entre os pesquisadores com relação a aspectos específicos da convivência humana como, por exemplo, a presença de uma tendência inata à competição ou à solidariedade, ou ainda com relação à capacidade individual e/ou coletiva de aprender e mudar o comportamento, frente a uma percepção mais conservadora onde o ser humano se movimentaria nos limites de uma matriz inata pouco flexível.

A necessidade mais evidente da fundamentação na definição filosófica do comportamento humano vai depender, em grande parte, das características do objeto a ser estudado e da riqueza de dados a que o pesquisador vai ter acesso. Ao estudar, por exemplo, um conflito entre trabalhadores e patrões por melhores salários, mediado por uma estrutura sindical numa situação de greve, o pesquisador não deverá ter grandes dificuldades para ilustrar os níveis de solidariedade internos a cada classe social, os mecanismos de solidariedade com relação a líderes e grupos específicos, assim como a atuação institucional e burocrática das organizações presentes no processo. É claro que dificilmente o autor vai poder furta-se de optar por uma análise com maior presença dos referenciais de origem marxista ou weberianos, mas a possibilidade de ter acesso aos dados e a riqueza das informações facilitam o desenvolvimento da pesquisa.

O estudo do recluso e do sistema prisional, contudo, é uma situação distinta. Por um lado, as informações são confusas e os papéis pouco delineados e, por outro lado, o acesso às informações é muito difícil pelas características inerentes às condições do próprio objeto na sociedade. 
Além disso, é preciso levar em conta também que questões envolvidas no estudo, como culpa e punição, justiça e o sofrimento humano estão muito presentes na formação política e religiosa do próprio pesquisador, levando a situações em que podem aflorar paixões. Ou seja, em resumo, é importante ter presente que há uma complexidade inerente específica do objeto de pesquisa aqui abordado, que condiciona e limita o processo de aproximação teórica.

\section{Visões sobre o presídio}

O conceito "sociedade dos cativos" (Sykes, 1999) busca configurar as condições de vida e de relacionamento social específicos das organizações penitenciárias, ressaltando que as características perversas destas condições permitem a emergência de valores sociais próprios da cultura delinqüente, que se chocam e, na maioria das vezes, suplantam os valores prevalecentes na sociedade inclusiva, tornando inviável o projeto de reintegrar

106 os indivíduos que vivenciaram a experiência prisional.

Os exemplos de situações que promovem a proliferação do ilícito no presídio são inúmeros, os mais significativos são a prostituição e o lazer. A prostituição ocorre desde a entrada do preso que é vendido pelos "urubus" (carcereiros) para relações homossexuais forçadas, como também devido às dívidas por drogas e/ou jogos de azar para uma homossexualidade de sobrevivência. Já nos momentos de lazer dos presos ocorre o uso das drogas; o jogo de cartas (Almeida, 2003); a homossexualidade voluntária; o movimento da economia delinqüente através das visitas dos presos (que trazem os objetos de escambo) e o futebol que encarna as relações de poder entre os detentos. Em todas estas situações existem as manifestações do aprendizado da delinqüência, da proliferação do ilícito e do afastamento da reabilitação.

Muitos motivos apresentam-se para explicar a proliferação da delinqüência no presídio, como por exemplo, uma cultura do crime fora dos muros que é incorporada na pri- 
são; o aparato de repressão do Estado; a pouca preocupação em fazer valer a Lei de Execução Penal na sua totalidade para o estabelecimento prisional; a superpopulação carcerária (Adorno, 1998; Coelho, 1987; Wacquant, 2004). Para os autores apontados anteriormente, a violência no presídio não é somente a sujeição a horários e não ter trabalho para todos. A violência, segundo esta visão, é o próprio sistema, desde os mecanismos de construção da lei e a forma de execução, até a preocupação em construir o presídio e os seus objetivos reabilitadores. A prisão é mais uma forma de reafirmação do sistema de dominação (Wacquant, 2004).

Fischer, no seu trabalho intitulado Poder e cultura em organizações penitenciárias, situa os problemas da instituição prisional por meio de outros parâmetros. Segundo a autora, há uma relação quase orgânica entre os diferentes agentes e a instituição prisional, através de uma organização individualizada, com funcionamento determinado por sua especificidade e pelo estilo de gerenciamento de sua administração. $\mathrm{Na}$ afirmação de Fischer (1989), podemos entender a instituição prisional voltada a uma política dominante e, ao mesmo tempo, as relações internas do presídio como guetos de proliferação do ilícito que não se abrem para qualquer vontade de mudança para o bem dos presos. "Isto torna, de um lado, totalmente desnecessárias políticas públicas que abranjam o setor como um todo e, de outro lado, cada organização um 'feudo' de poder e um 'gueto' de cultura organizacional específicos” (Fischer, 1989, p. 47). Fischer apresenta como exemplo a relutância dos agentes da prisão à entrada da Comissão de Direitos Humanos no presídio ou mesmo uma política integrada nas penitenciárias paulistas. As ligações podem ser estabelecidas por laços funcionais hierárquicos, de amizade, de parentesco e de lealdade, ou por uma inexplicável mistura destes (Fischer, 1989, p. 65).

A gestão do poder no presídio é formada de acordo com os agentes do presídio, a arquitetura prisional, a faci- 
lidade do escambo, o diretor do presídio e a efervescência da discussão da importância do presídio no cotidiano. Cada um dos segmentos apontados serve como facilitador desta cultura delinqüente. Por exemplo, um presídio que dificulta sobremaneira o acesso às drogas, permite uma concentração de poder entre os carcereiros corruptos e os presos envolvidos com o tráfico. Este acesso restrito dá a grupos específicos um controle da massa carcerária; já, se o acesso às drogas é mais fácil, o poder tende a diluir-se. Porém, com um maior consumo de drogas as dívidas aumentam e assim a violência volta-se para os inadimplentes, trazendo o poder para um outro grupo que são os malandros que controlam os "laranjas/robôs". Esta situação, longe de ser hipotética, mostra a dificuldade em viabilizar qualquer política pública na reclusão. A instituição penitenciária procura cada vez mais se fechar em torno de si mesma, constituindo-se em verdadeiros nichos, almejando a invisibilidade e o isolamento, 108 inclusive das outras instituições prisionais (Wacquant, 2004).

O livro Vigiar e punir de Foucault (1986) discute também a transformação das penitenciárias em feudos de poder, fazendo analogia do direito penal cientificamente racionalizado com a penalidade cientificamente humanizada. Coloca que as formas de poder modernas referem-se a um controle tecnocrático da evolução normativa e execução jurídica, mostrando a expansão do poder nas relações socais. O encarceramento, nestes termos, foi concebido como forma de castigo e como técnica de correção. Foucault trabalha com o poliformismo do poder em diferentes instituições e casos, pegando como exemplo a prisão. Para Foucault o direito penal é um instrumento de dominação, protege os direitos de propriedade da classe dominante, assim como as estruturas morais e sociais que o sustentam. O castigo está dirigido, sobretudo, contra estes indivíduos da classe desprivilegiada ou aqueles que representam ameaça política. O direito penal e o castigo representam uma complexa combinação de interesses 
sociais, por meio da sanção coercitiva e da representação simbólica, convertendo o castigo em uma forma de poder exercido, assim como de um poder manifesto (Foucault, 1986).

Garland (1999), recorre a conceitos e argumentos marxistas sem colocar-se em um único marco conceitual. Analisa como um modo de produção mutável deu origem a avanços políticos e ideológicos que incidiram diretamente sobre a política penal e social. A penalidade, para o autor, é um sistema dirigido pelo Estado, imerso em formas legais e marcos ideológicos. Um elemento dentro de um contexto de maior alcance de políticas sociais contra os pobres. Assim, o castigo é um fenômeno histórico específico que só aparece em formas particulares e concretas (Young, 1999).

Para facilitar a inserção da visão habermasiana ao objeto em foco, e contrapor e compor com os estudos apontados no item anterior, dividimos as obras entre céticos e reabilitadores à reclusão, como uma forma didática de separar o presídio em dois campos de entendimento e atuação. Pode-se, em termos muito gerais, perceber a discussão sobre a questão penitenciária composta por dois grupos distintos, a saber, (a) céticos ao sistema prisional, que não acreditam no Sistema como um todo e (b) reabilitadores, que acreditam na possibilidade de recuperação do preso e na função social do Sistema. (a) Os céticos discutem o aparato ideológico do sistema e a repressão controlada do Estado em função do conflito social e da estratégia de dominação. Assim, junto com as funções sociais para controlar o delito, operam instrumentos de exercício do poder de uma classe sobre outra. A pena está ligada à esfera legal, por este motivo o castigo contribui para legitimar a violência do Estado. (b) Os estudos que defendem a reabilitação adotam alguns símbolos que representam a possibilidade de re-socialização do indivíduo preso como, por exemplo, a) trabalho; b) assistência jurídica² ; ) assistência religiosa; d) assis-

\footnotetext{
${ }^{2} 47 \%$ dos presos estão sem julgamento (Jorge, 2000), muitos mandatos de prisão
} 
tência médica; e) separação dos condenados e não condenados; f) classificação dos presos; g) reformulação das penas; h) programas de alfabetização ${ }^{3}$; i) asseguração de todos os direitos não atingidos pela sentença; j) cooperação da comunidade na execução da pena; k) assistência material: vestuário, roupas e higiene; 1) iniciação profissional e aperfeiçoamento técnico; m) assistência social; n) tarefas comunitárias não remuneradas; o) respeito à integridade física e moral; p) sanção penal: não pode haver sanções coletivas, cela escura; q) direito a espaços que permitam a educação e o lazer ${ }^{4}$. Os reabilitadores apontam o não cumprimento e desleixo da sociedade para com a instituição prisional como um forte motivo de seu fracasso, acreditando que, se fosse respeitada a Lei de Execução Penal, seria possível pensar em reabilitação (Jorge, 2000). Outro aspecto que sustenta a tese dos reabilitadores é o questionamento do paradigma que a sociedade deve adotar para tratar dos sujeitos sociais que agridem as 110 normas constituídas pelo coletivo.

Se analisarmos o presídio pela Teoria da Ação Comunicativa, com um olhar diferente dos pressupostos teóricos da reclusão (céticos e reabilitadores), podemos inserir no presídio o conceito de ação, ampliando-o. Mostrando que não somente de ações estratégicas vive o presídio. O grupo de amigos, as formas de solidariedade, a própria linguagem desenvolvida são exemplos da existência do agir comunicativo e da cooperação, lembrando que o Mundo da Vida é o armazém do saber e da relação social e que as ações sociais estão, seja na forma comunicativa ou estratégica, ancoradas nele.

não cumpridos, muitos ficam mais tempo no presídio do que o imposto pelo judiciário, a maior parte dos presos não consegue os benefícios de sursis, comutação da pena, mudança de regime (Jorge, 2000), 95\% não possuem condição de pagar um advogado (Massola, 2001).

${ }^{3} 87 \%$ não têm o primeiro grau completo (Massola, 2001).

${ }^{4}$ Artigo 83 do Código Penal lei de Execução Penal: "O estabelecimento penal, conforme a sua natureza, deverá contar em suas dependências com áreas de serviço destinadas a dar assistência, educação, trabalho, recreação e prática esportiva". 


\section{A incorporação dos símbolos e a linguagem da prisão}

Do ponto de vista moral, uma transgressão aparece como violação individualmente imputável de normas intersubjetivamente reconhecidas (Habermas, 1987). O desvio da norma se mede pela ação do indivíduo, e o castigo faz parte do ressarcimento das conseqüências prejudiciais da ação. Este nível de juízo moral, a regulação consensual dos conflitos de ação, não se rege pela idéia do restabelecimento de um status quo antes lesionado, mas pela idéia de reparar a injustiça cometida, de curar a vulnerabilidade de uma norma (Habermas, 1987). Para Andrews (2002 e 2005), o processo de validação de normas morais, a partir de sua análise sobre a teoria habermasiana, inclui dois passos: o discurso de justificação e o discurso de aplicação. Para que uma norma tenha validade universal, é preciso que ela atenda ao "princípio de universalização" (U), definido como a situação em que todos os afetados podem aceitar as conseqüências e efeitos da norma causando a satisfação dos interesses de todos. $\mathrm{O}$ discurso de aplicação, por sua vez, busca atender ao princípio de propriedade, que consiste na avaliação da aplicabilidade de determinada norma moral a um contexto específico por meio de um processo de hierarquização de normas.

O Estado, representado pelo Juiz, vela pela integridade da ordem jurídica e seu poder não se apóia no prestígio e sim na legitimidade. Esta mudança é o ponto diferencial do direito tradicional para o direito moderno, que só pode constituir-se no nível moral pós-convencional ${ }^{5}$ (Habermas, 1989, pp. 146-155). Os órgãos do Estado organizados em termos de direito público constituem um plano no qual se estabelece um consenso. Deste consenso, promovido pelo Estado, acresce sua função integradora na sociedade moderna, respaldando-se nas leis e nas normas compartilhadas

\footnotetext{
${ }^{5}$ Para aprofundar os conceitos de pré-convencional, convencional e pós-convencional, ver Freitag (1992).
} 
pelo coletivo, sendo expresso no próprio sistema penal, bem como nas outras instâncias jurídicas, do qual faz parte também o sistema econômico, como o pagamento de uma multa ou indenização pecuniária.

As instituições jurídicas e as normas jurídicas, segundo Habermas, são legitimadas pelo coletivo. A legitimação ocorre no direito constitucional, nos princípios do direito penal e na legislação relativa aos assuntos penais próximo aos casos morais (estupro, roubo, assassinato, aborto). As ações Estatais, nestes casos, necessitam de uma justificação, conseguida pela legitimação e a aceitação da violência do Estado para conter os abusos morais, formando parte das ordens legítimas do mundo da vida e, junto com as normas informais que regem a ação, constituem a transformação da ação comunicativa na própria execução das normas. Em outras palavras, o Estado ao agir contra as ações ilícitas que afetam a integração do mundo da vida (estupro, assassinato, roubo, aborto), voltam a sua 112 ação para o consenso, para a cooperação. Deste modo, a ação do Estado é comunicativa, buscando os aspectos de verdade, veracidade e legitimidade, e se integram nos três planos comunicativos (mundo social, objetivo e subjetivo). Por este motivo, muito dos casos da ação Estatal no presídio referem-se a uma ação comunicativa ${ }^{6}$ e não necessariamente e sempre, como afirmam os céticos, a uma ação de dominação do Estado contra a classe pobre, o que daria a idéia equivocada, utilizando-se da taxonomia habermasiana, de ação estratégica.

Segundo Silva (2006), a norma depende da validade e da eficácia da lei, somente a validade não é suficiente para garanti-la, uma vez que indivíduos podem optar por agir estrategicamente sem consideração ao interesse geral, sendo necessário aplicar sanções para dissuadir comportamentos transgressores. Por outro lado, em uma democra-

\footnotetext{
${ }^{6}$ Estamos referindo apenas as ações do Estado para conter a transgressão das normas através do Código Penal; todas as outras ações estatais que não contemplam as normas legitimadas pelo coletivo são consideradas ações estratégicas.
} 
cia, apenas leis legítimas, isto é, aquelas que foram validadas discursivamente, podem aplicar sanções.

Andrews aponta que a dinâmica entre fato normativo e validade oferece os elementos necessários para a dinâmica social e construção das normas consensualmente, como neste fragmento:

"Deve-se ter claro que as normas formais exigem sanções. Atores sociais podem escolher a ação estratégica, ignorando as normas legitimadas pela comunidade política. Portanto, o bem-estar geral só pode ser garantido se atores autointeressados forem dissuadidos de agir contra o interesse geral por meio da aplicação de sanções. O interesse geral, por sua vez, só pode ser estabelecido mediante procedimentos de deliberação democrática. É essa dinâmica, entre a legitimidade discursiva das leis e a necessidade de aplicação de sanções, que Habermas identificou como sendo a tensão entre a validade e facticidade da lei” (2005, p. 274).

Em outras palavras, se há adesão espontânea a uma lei, pode-se supor que os destinatários desta a reconheçam como legítima e sejam capazes de justificá-la racionalmente. Se, por outro lado, há baixa adesão (ou seja, pouca "aceitação") a uma lei, é porque seus destinatários não a têm como suficientemente legítima e não encontram argumentos para justificá-la. Em suma, em uma comunidade política qualquer, para que normas formais (leis) sejam consideradas legítimas, elas precisam atender aos seguintes critérios: (a) devem ser submetidas a um processo deliberativo; (b) as regras do processo deliberativo devem ter sido validadas discursivamente; (c) as regras de deliberação foram institucionalizadas na forma de lei.

As normas que nascem no seio social podem ser normatizadas por meio de um conflito com a norma já vigente (Habermas, 1987). A troca de fundamentos legitimatórios não afeta de forma direta o todo ativo de normas jurídicas, 
mas pode representar um impulso para uma transformação legal (ou revolucionária em caso limite) do direito vigente (Habermas, 1987). Isto mostra que as normas são construídas no mundo da vida e que o Direito normativo está ancorado no Mundo da Vida.

A ambivalência do Estado (Habermas, 1987) - de garantia de liberdade e privação de liberdade - não pode fazer-se derivar de uma dialética entre o direito como instituição e o direito como meio, já que a violência do Estado de privação de liberdade só se pretende desde a perspectiva do mundo da vida através de ações comunicativas, quer dizer, só se almeja em relação com o que temos chamado de instituição jurídica ancorada no mundo da vida.

O problema social, para Habermas, é definido fundamentalmente por uma não internalização das normas no sentido pós-convencional, relacionando-se antes com os níveis morais desenvolvidos (Habermas, 1989) do que com 114 a situação econômica.

Interpretando a reclusão pelo olhar habermasiano de ação comunicativa, o presídio não deve ser entendido como reflexo de uma infra-estrutura que se justapõe a todas as relações sociais, através dos mecanismos de dominação e alienação. Ou mesmo como incorporação de uma cultura delinqüente que surge da própria transgressão das normas que estão desancoradas das relações sociais dos indivíduos livres. O presídio surge da formação de consenso do Mundo da Vida através das ações comunicativas dos atores sociais, que construíram discursivamente as normas que regem o agrupamento. O que ocorre, segundo esta interpretação, é uma colonização do Mundo da Vida pelo Sistema Dinheiro e Poder que se sobrepõe ao princípio que rege a reclusão, que é manter coesa e íntegra a sociedade. Esta colonização decorre, segundo Habermas (1987), (a) do nível moral dos sujeitos sociais e sua capacidade de argumentação consensual; (b) da perda de sentido para o agrupamento das 
regras construídas pelo coletivo; (c) da anomia em relação às ordens institucionais existentes para fazer face às necessidades de coordenar as ações nas novas situações. No entanto, o próprio presídio, como a construção das regras pelos sujeitos sociais reclusos, está ancorado no mundo da vida.

Um dos argumentos utilizados pelos teóricos céticos ao presídio é colocar o Estado como mecanismo de coerção das massas (Garland, 1999). Esta visão não é compartilhada segundo nossa leitura da teoria habermasiana, no qual o autor da Teoria da Ação Comunicativa aponta que as normas são construídas no mundo da vida através de formação discursiva de consensos. O entendimento é o princípio fundamental de criação de ritos e símbolos que é legitimado pelo Estado nas leis e códigos vigentes. Já os autores que crêem na reabilitação do condenado vêem o Estado como intermediador das normas penais para a manutenção do coletivo. Neste caso as normas são vistas de forma estática, não como possibilidade de transformação através da complexificação sistêmica e desenvolvimento do mundo da vida. As regras, com esta concepção de Estado, são arquipélagos incomunicáveis e estanques à reprodução do mundo da vida, entendendo o sistema através do processo de absolutização. Esta visão de Estado é criticada pelo próprio Habermas na Teoria da Ação Comunicativa (1987, Tomo II).

Outro ponto importante na compreensão da instituição prisional, através da análise habermasiana, é entendê-la a partir de uma estrutura normativa que é conciliada com as regras institucionalizadas pelo Estado e as relações intersubjetivas entre os presos e a instituição. Os presos se constituem em uma massa criminosa que não tem as regras comunicativas muito claras e estão, em muitos casos, em níveis baixos de amadurecimento moral em função da ausência de desenvolvimento cognitivo pós-convencional. O presídio é expressão das normas compartilhadas por uma sociedade, por isso o cárcere não é um arquipélago de ritos e símbolos, a reclusão 
é integrada à lógica evolutiva na qual se inclui uma distinção entre níveis de aprendizagem e os processos que são possíveis em cada um desses níveis (Habermas, 1987).

“[...] a evolução social pode ser considerada como um processo de aprendizagem bidimensional (cognitivo/ técnico e prático/moral), cujos estágios podem descreverse estruturalmente e ordenar-se de acordo com uma lógica evolutiva. As estruturas de consciência coletivamente compartilhadas são entendidas como níveis de aprendizagem, isto é, como condições estruturais de processos de aprendizagem possíveis" (McCarthy, 1987, p. 287).

McCarthy, ao interpretar a Teoria da Ação Comunicativa, aponta a capacidade dos grupos humanos de criar condições para aprendizagem, desenvolvendo estruturas de consciência e elevando-os para níveis morais superiores. Isso 116 revelaria uma potencialidade de aumentar as ações comunicativas dentro do presídio e reverter a lógica perversa das ações estratégicas. Isto quer dizer que os indivíduos presos, mesmo não atingindo o grau de desenvolvimento cognitivo pós-convencional, devido ao desrespeito às regras, vivendo sob a colonização do mundo da vida, construindo sua vivência social a partir de ações racionais voltadas ao próprio êxito, têm a potencialidade de elevar as ações comunicativas e construir espaços para o entendimento mútuo e para o diálogo livre de coerções.

Segundo a leitura habermasiana, a reabilitação deveria promover a incorporação das regras compartilhadas no mundo da vida. Porém, ocorre um distanciamento das normas compartilhadas porque os reclusos não possuem um ambiente propício para a transformação. Deste modo a reclusão serve como instituição de valorização das normas, tendo como objetivo ser o espelho social para reforçar nos indivíduos livres as regras impostas. Assim, a maior função 
social do presídio é de espelho das ações sociais não aceitas pelo agrupamento e do próprio sentido de justiça retributiva. Seu aspecto reabilitador pode assim estar defasado porque a sociedade, como expressão da maioria, ilustra um comportamento de amadurecimento moral de nível préconvencional, conforme a nomenclatura de Kholberg apropriada por Habermas (1989).

Neste caso pode-se afirmar que o preso é a corporificação da transgressão e influi na existência do castigo, servindo como espelho social para o coletivo, buscando, através do cárcere, um estado de consciência coletiva não incorporada no mundo da vida.

Para exemplificarmos as afirmações referentes às ações comunicativas e estratégicas no presídio foram analisadas, na pesquisa de campo na Casa de Detenção de São Bernardo - Campinas, as atividades no tempo de lazer dos presos. Um exame rápido aponta os mecanismos de integração e construção de consenso, ao lado das formas de poder manifestas dos atores sociais. Nestes termos, o lazer é, por um lado, um indicativo de reabilitação ao pensar em uma ação com significado "terapêutico", como a atividade física, os jogos de tabuleiro ou as visitas. Por outro lado, as atividades de lazer são também ilícitas, como o carteado e as drogas. Com a ressalva de que o lazer não é licito ou ilícito em si, o lazer é a busca pelo prazer, são as ações dos sujeitos sociais no meio que adjetivam a licitude ou não da atividade de lazer.

O lazer torna-se um importante objeto no presídio se entendermos as diferentes atividades praticadas pelos presos, que buscam auferir prazer como lazer. As atividades para os presos são momentos importantes no seu tempo, pois o lazer reforçaria a idéia de grupo, aproximando-os das relações fora dos limites da instituição (Goifman, 1998). Este é um dos maiores argumentos dos reabilitadores: permitir a aproximação do mundo de fora da prisão, impedir a todo custo a criação de uma identidade intramuros que o 
defina por sua delinqüência. Todavia, o lazer pode ser visto por outro ângulo. O lazer também é promotor do ilícito, através dos jogos de azar, da prostituição voluntária e das relações da malandragem no futebol, como vêem os céticos. Pela visão habermasiana proposta, as atividades de lazer têm sua origem primeira no mundo da vida, porque não existe dúvida sobre a potencialidade lúdica do homem e a sua busca pelo prazer; porém, a riqueza original decorrente da construção discursiva de consensos pode vir a ser colonizada na perspectiva sistêmica das ações estratégicas.

Com os subsídios da leitura da Teoria da Ação Comunicativa, pudemos perceber o mundo compartilhado dos presos e, ao mesmo tempo, compreender as suas ações racionais estratégicas e as ações comunicativas. É importante ter como perspectiva que a incorporação de hábitos e da linguagem na prisão, ou em qualquer agrupamento humano, tem como função principal a definição da comunidade enquanto grupo, isto é, a partir

118 de uma linguagem e símbolos, os indivíduos dotados de razão se definem enquanto comunidade organizada, desempenhando seus papéis sociais e se caracterizando enquanto sujeitos. Desta forma, os agentes sociais constroem o mundo da vida através das regras sociais compartilhadas (mundo objetivo), da vivência com seus pares (mundo social) e com a experiência individual do seu entorno (mundo subjetivo).

\section{Pesquisa de campo: experiência no presídio}

Como procuramos ilustrar antes, ao debruçar-se sobre as teorias do lazer, percebe-se uma tendência de colocar o trabalho como categoria fundamental. Assim, o lazer só existiria se houvesse o seu contraponto, o tempo de trabalho. Portanto, fica nítido que grupos que não tenham o trabalho formalizado, desempregados ou estejam em situações limites (presídio) não teriam o tempo de lazer. Este foi o primeiro motivo de estudar o presídio; o segundo motivo foi incorporar ao debate sobre a reclusão as categorias habermasianas do Mun- 
do da Vida/Sistema e ação comunicativa/ação estratégica. O lazer é um importante referencial para analisar as formas de comunicação em situações limites como a reclusão, porque há certo consenso em que o lúdico, o prazer e o divertimento, que são componentes do lazer, integram o entendimento de Mundo da Vida (Almeida e Gutierrez, 2004). A constatação da presença do lazer no presídio nos permitiria afirmar que as relações sociais em seu interior são ancoradas no Mundo da Vida, levando a construir uma visão distinta daquela apresentada pelos autores que veiculam análises voltadas mais para uma percepção cética do objeto, assim como também possibilita distanciar-se do olhar especificamente reabilitador. Trata-se, portanto, de analisar a reclusão também pela integração, formação de consensos e construção das personalidades, e não somente pelas suas características estratégicas ou ligadas ao poder manifesto no cárcere.

Este estudo foi realizado na Casa de Detenção de São Bernardo (Penitenciária Regime Fechado - Modelo Espinha de Peixe $^{7}$ ), também conhecido como "Cadeião de Campinas". No período de pesquisa, primeiro semestre de 2002, a situação dos presídios era bem diferente da encontrada hoje; a entrada està muito mais controlada devido ao perigo de rebelião e ao crime organizado. Os dados refletem uma realidade histórica datada no tempo. Pode ser que as atividades e as regras de convivência tenham se alterado devido aos acontecimentos recentes; no entanto, os códigos e símbolos do presídio se reproduziram no tempo e, mais do que uma alteração na estrutura do presídio, ocorreu um aprofundamento daquilo denominado 'sociedade dos cativos', fato este que, ao nosso ver, reforça a necessidade de uma análise baseada num referencial diferente, ao abordar o lazer na prisão pela teoria habermasiana.

\footnotetext{
${ }^{7}$ O Modelo Espinha de Peixe encontra-se no trabalho de Jorge (2000). Nesta defesa de livre-docência o autor apresenta modelos de presídios. O presídio parece uma espinha de peixe, por isso o nome: a parte coletiva (pátio) é a espinha central, e os seus ramos são as celas.
} 
Para facilitar a visualização das atividades de lazer no presídio, foram divididas, em termos gerais, em dois tipos: (1) as formais e (2) as informais.

(1) As formais representam as atividades sugeridas (ou aceitas) pelo corpo técnico competente, ou por instituições que, no presídio, se inserem. São: a) campeonatos de futebol, b) hora do pátio, c) visitas, d) festas e e) televisão.

a) Futebol. Os campeonatos são freqüentes no Cadeião. A quadra de salão fica no centro do pátio. A divisão dos times segue uma estrutura de poder da malandragem, que ficou clara quando um detento apresentou "seu" time. Esta afirmação me fez lembrar Coelho (1987) que discute a compra e venda de jogadores por maços de cigarros. Existe uma economia delinqüente para conseguir os melhores jogadores.

b) Hora do pátio. Na hora do pátio ocorrem diferentes atividades: a musculação com alteres de cimento e em algumas barras enferrujadas; temos também as pessoas que 120 correm; o futebol; ficar de "bobeira"; jogar dama e xadrez.

Goifman (1998) discorre sobre as atividades de musculação no presídio, apontando-a como uma forma de demonstrar força para se proteger, assim ter um corpo forte na prisão não é para estética, mas proteção. Esta leitura da atividade do halterofilismo está equivocada. Primeiro, o código de poder não é pela força, mas pelo proceder da malandragem. Segundo, a estética é importante, porque os presos não estão aquém da cultura do culto ao corpo, eles possuem televisão e trazem consigo os atributos estéticos da cultura "livre". A presença do culto estético mostra-nos que é necessário revermos algumas questões quando se discute a "sociedade dos cativos". Outro pensamento freqüente é afirmar que todas as regras da penitenciária são por princípio prisionizadas. Esta afirmação coloca o cárcere como estanque das relações humanas. Esta é uma das críticas aos estudos de Goffman (Almeida, 2003), por pensar a relação dos internos através da unilateralidade da formação dos 
símbolos das instituições totais, sem intermediação das normas compartilhadas pela totalidade do coletivo.

A partir do referencial habermasiano, devemos compreender o indivíduo preso pela sua capacidade de razão e racionalidade, que é construída no mundo da vida e não na reclusão. Afirmar que as regras do cárcere sobrepõem-se de forma absoluta ao mundo da vida é similar a aceitar a possibilidade da construção do saber a partir da colonização absoluta do mundo das relações por qualquer instância social em que o indivíduo se encontra (trabalho, presídio, escola, empresa). É acreditar que o mundo da vida não se desenvolve e evolui, apenas se reproduz no Sistema. O mundo da vida é o armazém do saber, onde a sociedade se constrói através das ordens legítimas reguladas e disseminadas pela comunicação (Habermas, 1990, p. 96). O mundo das relações e entendimentos é anterior à ação voltada para a dominação, por isso a personalidade é construída no mundo da vida, e nela e por ela é transformada.

c) Visitas. Além de ser um momento importante de reencontro, de trazer as novidades de fora (Goifman, 1998), as visitas servem como marcador de tempo e movimentam toda a economia delinqüente. Ela é movida pelo dinheiro que as visitas trazem, ou outros objetos que podem ser ilícitos ou não, que servem como forma de escambo. Depois das visitas todos os pagamentos devem ser quitados, dívidas de jogo e drogas principalmente. A visita é um importante dia na vida do preso. Nas revistas feitas às visitas, ocorre o processo de sofrimento das famílias, é a chamada extensão da reclusão para os familiares dos presos (Coelho, 1987), muitas delas trazem pedaços de comida separados para deixar com os carcereiros, para que eles nas revistas não estraguem todos os pertences que o familiar trouxe ao recluso (Paixão, 1987).

As visitas têm um papel importante no presídio, como também no lazer do preso, não somente pela própria visita ou pelo lazer gastronômico, como também pelo sexo. Já que pela reforma na execução penal foi autorizada a visita íntima. 
d) Festas. As festas ocorrem em dias especiais como o dia dos pais e das crianças, quando a família fica o dia inteiro com o preso. Sempre há atividades com as crianças, apresentações de pessoal de fora, ajuda de ONG e, a maior parte das vezes, grupos de RAP vêm se apresentar. Há uma tentativa por parte dos presos de tentar minimizar o ambiente prisional, talvez para alegrar as visitas, ou porque os presos queiram desvencilhar-se dos símbolos que representam a reclusão. Os internos não se identificam com o cárcere, nem com suas relações de poder (Goifman, 1998).

(2) As atividades denominadas informais representam ações desenvolvidas pelo coletivo na cela, ou por grupos de convivência. São atividades que normalmente promovem o ilícito, pode-se citar: a) Homossexualidade voluntária; b) os jogos de azar; c) o uso de diferentes tipos de drogas e d) a confecção das tatuagens.

"O tempo disponível dos detentos não é responsável exclusivo pela proliferação de atividades ilegais na prisão. O que pode ser notado é que práticas associadas ao uso do tempo, como jogos e drogas, transcendem a idéia de passatempo transformando-se em atividades cujo controle determina significativamente as relações de poder no cárcere” (Goifman, 1998, p. 216).

a) Homossexualidade voluntária. Colocamos o termo voluntário para discernir do estupro, ou mesmo daquela homossexualidade que ocorre motivada pela falta de pagamento no jogo, ou drogas. Muitas formas de pagamento das dívidas existem no presídio, além da homossexualidade, a troca de produtos trazidos pelas visitas, o dinheiro. Há ainda o "laranja", ou "robô", que resumidamente é a pessoa que assume um delito dentro da prisão como a morte de alguém, ou o tráfico de drogas, para saldar seu débito. Ao assumir alguns destes atos, o robô aumenta seu tempo de 
reclusão ou no mínimo não conseguirá os benefícios de mudança de regime prisional. Por isso, uma das formas de ver o quanto alguém tem força no presídio é saber quantos laranjas o sujeito tem sob seu controle.

O sexo na prisão é uma extensão das ruas e prostíbulos. "Atrás do come quieto (cortina improvisada nas celas coletivas)", diz um recluso, "tudo pode acontecer". Existe o ato sexual como marido e mulher, "Fanchona", em que o preso "casa" dentro do presídio para se proteger. Temos também aqueles que vendem seu corpo para outros se prostituindo.

A homossexualidade é um tabu na sociedade, o lazer também acompanha este tabu. A maioria dos estudos sobre lazer permanece distante desta situação, definindo as atividades de lazer pelas suas ações palpáveis e morais no cotidiano, não entendendo o lazer como busca de um prazer que passa, também, pela idéia de orgasmo e que pode ser consumado pelas práticas sexuais de qualquer natureza.

b) Jogos de azar. Um dos presos me disse que o truco é o mais jogado, não afirmou que vale dinheiro, mas disse que "jogavam pra valer". Pela literatura, os jogos, na sua grande maioria, valem dinheiro (Coelho, 1987), por isso existem dívidas e elas devem ser saldadas. Há muitas gírias utilizadas pelos presidiários no jogo de truco que trafegam no nosso cotidiano, como: pica-fumo, ficar de valetes, copas. São linguagens do cotidiano da prisão que se referem ao jogo e a situações à parte do jogo ${ }^{8}$ que são incorporadas fora da prisão. Um fato importante no jogo é a presença do "xerife" da cela. O "xerife" além de ter as regalias, como escolher onde vai dormir e seu prato de comida, é o responsável por cuidar das apostas nos jogos, ele fica com uma porcentagem de cada rodada apostada (Coelho, 1987).

\footnotetext{
${ }^{8}$ Pica fumo: matar alguém; Ficar de valetes: posição para dormir em celas apertadas; Copas: mulherzinha.
} 
O preso sempre busca o mundo externo para conviver na reclusão. Os símbolos construídos no cotidiano livre são referências constantes dos internos e por isso são eles que formam (juntamente com diversos fatores apontados como o espaço, a vigilância, o poder, a distância) a cultura delinqüente. A linguagem na reclusão é aprimorada e evoluída pelo contato do preso com o mundo externo, que ocorre com as visitas, cartas de parentes, presos novos, agentes penitenciários e televisão.

c) Drogas. As drogas fazem parte do cotidiano da prisão; presenciei uso freqüente da maconha no pátio e da Maria louca ${ }^{9}$. Sabe-se que a maconha é parte da cultura prisional e quando está em falta é motivo de conflito na prisão, é como um calmante para as massas, afirma o recluso. É também uma das maiores fontes de dívidas e conflitos (Goifman, 1998). Existem diferentes grupos que controlam a droga; para Jocenir (2001), junto com o futebol, os traficantes dos presídios são o grupo mais próximo da malandragem, pois 124 necessitam de respaldo para os procederes do código da prisão, como mandar uma "sugesta"10", encontrar um "laranja", ou mesmo ter a permissão para "apagar” alguém.

Outro tabu na maioria dos estudos sobre o lazer é o uso das drogas (lícitas e ilícitas) como elemento de uma prática de lazer. Se considerarmos que o uso das drogas, de modo geral, não é atividade de lazer, tanto as bebidas alcoólicas como cigarro não seriam lazeres. Esta afirmação nega o caráter de sociabilização da bebida e o prazer que ela traz. Por isso, esta colocação nos aparece infundada, visto que o lazer não é caracterizado pelo seu aspecto lícito e ilícito. $\mathrm{O}$ lazer, por encontrar-se nas atividades espontâneas no mundo da vida, não é definido somente pelo seu caráter normativo direcionado ao respeito às normas do direito posto, mas pelo seu sentido de dualidade sacro/profano (mundo

\footnotetext{
${ }^{9}$ Maria Louca, espécie de bebida alcoólica feita artesanalmente utilizando-se de casca de frutas e álcool etílico.

${ }^{10}$ Ação de repreensão.
} 
normativo), por sua possibilidade de socialização e de intersubjetividade (mundo social) e também, pela vontade pessoal, que perpassa pelo mundo social e normativo e o integra na escolha do sujeito (mundo subjetivo). Este mesmo pensamento pode ser ampliado para o sexo como atividade de lazer, pois que ele encarna a dualidade Sacro/Profano.

Todas estas atividades de lazer têm um grande papel na cultura da prisão. São as atividades de lazer que definem o grupo que controla a prisão, "malandragem" e os subjugados (Jocenir, 2001). Outro motivo é referente à atividade de lazer como controle da massa encarcerada por parte dos agentes penitenciários, porque as primeiras sanções coletivas atuam diretamente nas atividades de lazer (Goifman, 1998), como proibir a televisão, o horário de pátio e as visitas.

O lazer, no contexto apresentado, é entendido pela busca do prazer, que pode ou não ser consumado, pensando o agente como histórico e dotado de razão, que segue suas vontades, seus símbolos e padrões culturais, ou suas ações restritas às sanções e normas sociais (Gutierrez, 2001, p. 15). Isto é, o lazer está no mundo da vida e tem como limite as normas do grupo, o momento histórico e a ação do indivíduo.

"As atividades de lazer caracterizam-se por uma liberdade relativa de opção, pela percepção individual e subjetiva da expectativa de prazer e pela autonomia e responsabilidade do agente sujeito da ação social. Isto coloca grande parte das manifestações do objeto lazer no campo da sociabilidade espontânea, ou informal, compreendida aqui como espaço de interação distinto dos sistemas organizados formalmente, ou burocratizados, a exemplo das dimensões políticas e econômicas, definidas por Habermas como sistemas dirigidos pelos meios poder e moeda" (Gutierrez, 2001, p. 88).

O lazer do recluso é um lazer que é determinado pelos padrões de convivência do preso, juntamente com as relações 
no mundo da vida fora do ambiente prisional. Podemos dizer que o lazer e o ilícito seguem lado a lado na formação da sociedade dos cativos, isto é, o lazer estudado no presídio se relaciona às regras dos cativos na instituição prisional conjuntamente às manifestações do lazer nos espaços de interação e sociabilidade espontânea. Por conseguinte, o lazer, o ilícito, a prisão e o preso unem-se para formar os padrões e normas culturais do agrupamento dos indivíduos na reclusão.

Deve-se ter em mente que o presidiário vem da sociedade livre (mundo da vida e sistemas) com suas regras de convivência incorporadas. O lazer faz parte do seu cotidiano e é expresso e construído no mundo da vida. Afirmar que não existe o lazer na penitenciária é dizer que o recluso, ao entrar no presídio, retira toda a sua vivência do mundo social (como uma roupa) e incorpora as novas regras intramuros (vestindo a nova roupa, para utilizar a mesma metáfora), o que não é verdade.

126 O cárcere não é um arquipélago de ritos e símbolos, mas um local de interação e uma instituição que não está aquém da sociedade. Pois a sociedade dos cativos é construída na reclusão sim, mas com pessoas um dia livres e que minimamente têm acesso aos bens culturais de fora, seja nas visitas, na televisão, com os carcereiros ou com a entrada de novos presos. Como já foi esclarecido, as regras intramuros, ou melhor, a incorporação dos hábitos locais e definição do indivíduo com seu entorno, não é ato típico da reclusão, mas faz parte da forma de construção da linguagem e dos símbolos que compõem a nossa sociedade (Habermas, 1987, Tomo II, p. 22). Lembrando também que as regras valorizadas na prisão são construídas no mundo da vida, pois a reclusão é a manifestação palpável das normas legitimadas por um coletivo. O ideal de lazer que está colocado no presídio, inclusive definido por Goifman (1998) como o momento em que o preso tenta "matar o seu tempo", é permeado pela relação de poder e faz parte do cotidiano do presídio. 


\section{Observações finais}

Este texto procura trabalhar, em essência, duas relações específicas: (a) entre as definições de uma mesma categoria de análise a partir de escolas de pensamento distintas e (b) entre teoria e realidade, nos limites de um referencial metodológico específico.

No primeiro caso (a), a relação pode ser percebida na discussão sobre a definição do objeto lazer no contexto de uma produção intelectual que privilegia a categoria trabalho enquanto macrosociologicamente determinante, frente à sua percepção no interior de um referencial metodológico que adota outra categoria como central, ilustrado aqui por Habermas e a ação comunicativa. No segundo caso (b), o texto procura mostrar como a apreensão da realidade do presídio, a partir do referencial metodológico apresentado por Habermas, após a publicação da Teoria da Ação Comunicativa, permite perceber a presença das práticas de lazer no interior de uma instituição classificada como total, e avançar na sua reflexão de uma forma distinta das mais divulgadas até o momento.

É claro que método e objeto constituem uma totalidade. A opção pelo objeto lazer é apropriada a um tratamento metodológico que tem como categoria central o mundo da vida, e os autores desta pesquisa intuem, previamente, a possibilidade de apresentar um novo olhar da instituição presídio. O texto procura participar do debate sociológico contemporâneo, incorporando as pesquisas já existentes tanto sobre o tema lazer como sobre o tema presídio, trazendo como principal contribuição o fato de associar a questão da reclusão a dois elementos específicos: a questão do lazer e o referencial habermasiano. É uma construção que procura ser coerente, tanto ao marcar as diferenças com a produção que a antecede no campo, como na interação entre o recorte do objeto (o lazer na reclusão) e o referencial metodológico adotado (Habermas). 
É um exercício teórico e não apresenta nenhuma alternativa de intervenção concreta no campo. Isto não impede que seus autores guardem a esperança ou, quiçá, a pretensão de que a reflexão teórica aqui elaborada permita pensar novas práticas na relação com a população carcerária, e, explorando o potencial de amadurecimento moral presente nas relações comunicativas e na construção discursiva de consensos entre subjetividades intactas, possa-se chegar a construir uma situação de vida dos reclusos melhor, se comparada ao que se assiste hoje em dia.

\section{Gustavo Gutierrez}

é professor titular da Faculdade de Educação Física da Unicamp-SP

\section{Marco Bettine de Almida}

é doutor pelo programa de Pós-graduação da Faculdade de 128 Educação Física da Unicamp-SP

\section{Referências bibliográficas}

ADORNO, P. S. 1998. "Prisões, violência e direitos humanos no Brasil". PINHEIRO, P.; GUIMARÃES, S. (orgs.). Direitos humanos no século XXI. Brasília: IPRI.

ALMEIDA, M. B. 2003. "O prazer no ilícito: as práticas de lazer no presídio”. Licere, Belo Horizonte, vol. 6, $\mathrm{n}^{\circ}$ 1, pp. 71-81.

2007. "Lazer e Pós-modernidade". Efdeportes, Buenos Aires, vol. $11, \mathrm{n}^{\circ} 105$.

ALMEIDA, M.; GUTIERREZ, G. 2004. "Subsídios teóricos do conceito cultura para entender o lazer e suas políticas públicas". Conexões, Campinas, SP, vol. 2, $\mathrm{n}^{\circ} 1$.

. 2005. "A busca da excitação em Elias e Dunning: uma contri-

buição para o estudo do lazer, ócio e tempo livre”. Efdeportes, Buenos Aires, vol. $10, \mathrm{n}^{\circ} 80$.

2002. "A ética do discurso e o modelo dos consensos democrá-

ticos: uma réplica a J. Eisenberg”. Dados, Rio de Janeiro, vol. 45, $\mathrm{n}^{\circ} 4$, pp. 577-597.

ANDREWS, C. W. 2005. "Implicações teóricas do novo institucionalismo: 
uma abordagem habermasiana”. Dados, Rio de Janeiro, vol. 48, n², pp. 271-299.

ANTUNES, R. 1995. Adeus ao trabalho? Ensaios sobre a metamorfose e centralidade do mundo do trabalho. Campinas, SP: Cortez.

COELHO, E. C. 1987. A oficina do diabo: crise e conflito no sistema penitenciário do Rio de Janeiro. Rio de Janeiro: Espaço e Tempo/Iuperj.

DUMAZEDIER, J. 1979. Sociologia empírica do lazer. Tradução de Silvia Mazza e J. Guinsburg. São Paulo: Perspectiva/Sesc.

EISENBERG, J. 2001. "Justificação, aplicação e consenso: notas sobre democracia e deliberação". Dados, Rio de Janeiro, vol. 44, n 1.

ELIAS, N.; DUNNING, E. 1992. Memória e sociedade a busca da excitação. Lisboa: Difel.

FISCHER, R. 1989. Poder e cultura em organizações penitenciárias. Tese de Livre-Docência. Faculdade de Economia e Administração da Universidade de São Paulo.

FOUCAULT, M. 1986. Vigiar e punir: história da violência nas prisões. $4^{\mathrm{a}}$ ed. Tradução de Ligia M. Vassalo. Petrópolis, RJ: Vozes.

FREITAG, B. 1992. Itinerários de Antígona: a questão da moralidade. Campinas, SP: Papirus.

GARLAND, D. 1999. Castigo y sociedad moderna: un estudio de teoría social. Traducción de Berta Ruiz de la Concha. México D.F.: Siglo Veintiuno Editores.

GOFFMAN, E. 1996. Manicômios, prisões e conventos. $5^{\mathrm{a}}$ ed. São Paulo: Perspectiva.

GOIFMAN, K. 1998. Valetes em slow motion. Campinas, SP: Ed. Unicamp.

GORZ, A. 1982. Adeus ao proletariado: para além do socialismo. Rio de Janeiro: Forense.

GUTIERREZ, G. 2001. Lazer e prazer questões metodológicas e alternativas politicas. São Paulo: Edusp.

. 2002. "A contribuição da teoria da ação comunicativa para a pesquisa sobre o lazer". In: BRUNHZ, H. (org.). Lazer e ciências sociais. Campinas, SP: Autores Associados.

HABERMAS, J. 1987. Teoría de la acion comunicativa. Versión Castellana de Manoel Jemenez Redondo. Madri: Taurus. Tomos I e II.

1989. Consciência moral e agir comunicativo. Tradução de Guido A. de Almeida. Rio de Janeiro: Tempo Brasileiro. 1990. Pensamento pós-metafísico: estudos filosóficos. Tradução de Flavio Beno Siebeneichler. Rio de Janeiro: Tempo Brasileiro.

JOCENIR. 2001. Diário de um detento: o livro. São Paulo: Labor Texto Editorial.

JORGE, W. 2000. O sistema penitenciário do Estado de São Paulo e os projetos de estabelecimentos prisionais: avaliação da contribuição profissional em proje- 
tos para o sistema. Tese de Livre-Docência. Faculdade de Arquitetura e Urbanismo da Universidade de São Paulo.

LAFARGUE, P. 2000. O direito à preguiça. $2^{\text {a }}$ ed. Tradução de Teixeira Coelho. São Paulo: Unesp.

MARCELLINO, N. 1987. Lazer e educação. Campinas: Papirus.

MASSOLA, G. 2001. Sistema penitenciário: reforma ou reprodução. Um estudo da APAC de São José dos Campos. Dissertação de Mestrado. Instituto de Psicologia da Universidade de São Paulo.

MCCARTHY, T. 1987. La teoría crítica de Jürgen Habermas. Tradução de Manuel Jiménez Redondo. Madri: Editorial Tecnos.

MORIN, E. 1997. Cultura de massa no século XX: neurose. 9ª ed. Rio de Janeiro: Forense Universitária.

MURPHY, J.; NIEPOTH, W.; JAMIESON, L. 1991. Leisure system: critical concepts and applications. New York: Sagmore Publishing.

OFFE, C. 1989. Trabalho e sociedade: problemas estruturais e perspectivas para a sociedade do trabalho. Rio de Janeiro: Tempo Brasileiro.

PAIXÃO, A. L. 1987. Recuperar ou punir? Como o Estado trata o criminoso. São Paulo: Cortez/Autores Associados.

PLAYFAIR, G.; SINGTON, D. 1969. A prisão não cura, corrompe. São Paulo: Ibrasa.

130 REQUIXA, R. 1980. Sugestões e diretrizes para uma politica nacional de lazer. São Paulo: Sesc.

SILVA, B. (org.). 1987. Dicionário de ciências sociais. Rio de Janeiro: FGV/MEC.

SILVA, F. C. 2006. "Habermas, Rorty e o pragmatismo americano". Dados, Rio de Janeiro, vol. 49, $\mathrm{n}^{\circ}$ 1, pp. 99-117.

SYKES, G. M. 1999. The society of captives: a study of a maximum prison. New Jersey: Princeton University Press.

YOUNG, J. 1999. The exclusive society: social exclusion, crime and difference in late modernity. London/New Delhi: Thousand Oaks/Sage Publication.

WACQUANT, L. 2004. "Aberração carcerária à moda francesa”. Dados, Rio de Janeiro, vol. 47, n $^{\circ}$, pp. 215-232.

WALSH, R. 1986. Recration economic decision: comparing benefits and cost. Oxford London: Colorado State University.

WERNECK, C.; STOPPA, E.; ISAYAMA, H. 2001. Lazer e mercado. Campinas, SP: Papirus.

\section{Sites}

www.unicamp.br/fef/conexoes

www.efdeportes.com 


\section{CULTURA E LAZER: UMA APROXIMAÇÃO HABERMASIANA}

GUSTAVO GUTIERREZ E MARCO BETTINE DE ALMEIDA

$\mathrm{O}$ artigo apresenta uma reflexão sobre as relações entre cultura e lazer a partir de um referencial metodológico apoiado em Habermas. Adota o presídio, mais especificamente a Casa de Detenção de São Bernardo, como um espaço dotado de cultura própria (cultura delinqüente). Conclui apontando a importância das interações comunicativas, típicas da sociabilidade espontânea, presentes nas atividades de lazer, conforme as categorias apresentadas por Kholberg e incorporadas por Habermas, nos limites de um marco jurídico construído a partir de consensos originais do mundo da vida.

Palavras-chave: Cultura; Cultura delinqüente; Lazer; Presídio; Habermas. 


\section{CULTURE AND LEISURE: A HABERMASIAN APPROACH}

The article presents a reflection about the relationship between culture and entertainment from a methodological reference supported by Habermas' categories. It adopts the prison, specifically the Detention House of Sao Bernardo in Sao Paulo State, as a practical reference as a site which has its own culture (Delinquent culture). It concludes showing how important the communicative interactions are, when typical of a spontaneous sociability found on leisure activities, as the categories presented by Kholberg and incorporated by Habermas, within the limits of a legal framework built from the original consensus of life world.

Keywords: Culture; Delinquent culture; Leisure; Prison; Habermas. 